\title{
Monoclonal antibody B72.3 in benign breast lesions
}

S Soomro, S Shousha

\begin{abstract}
It has been suggested that the monoclonal antibody B72.3 may be useful as a diagnostic tool in fine needle aspirates of breast masses because it recognises "tumour associated glycoprotein (TAG)72". The antigen was sought in paraffin wax sections of 43 normal and benign breast biopsy specimens, using the avidin-biotin complex technique, to assess the extent of its presence in nonmalignant tissue. Strong focal staining was seen in $21(49 \%)$ cases. In 29 cases of fibrocystic change staining was present in $17(59 \%)$. All areas of apocrine metaplasia were positive, as well as a few normal ducts and acini and occasional areas of adenosis. Focal positivity was present in five out of 12 foci of ductal epithelial hyperplasia and in three out of seven radial scars. Staining was absent in two areas of lobular hyperplasia, three areas of sclerosing adenosis, and in a focus of lactational change. Focal positivity was also seen in two out of five fibroadenomas and in two out of three intraduct papillomas. Five normal subareolar sections and a section of normal lactating breast were negative.

It is concluded that B72.3 monoclonal antibody can show focal reactivity with a variety of normal and benign epithelial mammary structures, and it is doubtful that its use would be of any help in differentiating benign from malignant cells in fine needle aspirates.
\end{abstract}

B72.3 is a murine IgG monoclonal antibody which was generated by using metastatic tumour tissue from a human mammary carcinoma. The antibody recognises a high molecular weight antigen, designated tumour associated glycoprotein (TAG)-72, which is rich in carbohydrate and has mucin-like biochemical and biophysical properties. ${ }^{1-4}$ The antigen has been identified in most carcinomas of a variety of organs including breast, ovaries, oesophagus, stomach, colon, pancreas, as well as in non-small cell bronchogenic carcinoma. ${ }^{5}$

It has been suggested that immunostaining with this antibody may be useful in fine needle aspirates of breast masses to differentiate between malignant and benign cells. ${ }^{6-8}$ But there have also been reports which suggest that the antigen is present in some benign breast lesions. ${ }^{599}$ This study aimed at assessing the extent of the antigen in histological sections of a variety of non-malignant breast tissues. The assumption was that any positive staining seen in these tissues would have been reflected in the aspirates if these were taken. On the other hand, studying histological sections rather than aspirates provides more definitive and specific diagnosis which would allow the type of lesion or cell that is more likely to give rise to positive staining to be identified more accurately.

\section{Methods}

Paraffin wax sections of 43 routinely processed, formalin fixed normal and benign breast biopsy specimens were examined. The cases were selected so as to represent a variety of benign lesions, and some were derived from non-neoplastic areas of breasts with malignant disease elsewhere. The benign lesions included 29 cases of fibrocystic change, five fibroadenomas, and three intraduct papillomas. The normal tissue was derived from mastectomy specimens in five cases and from a lactating breast in the sixth case.

Sections $5 \mu \mathrm{m}$ thick were cut from each case, dewaxed in xylene, and rehydrated in graded alcohols. Endogenous peroxidase activity was blocked by $0.3 \%$ hydrogen peroxide in methanol for 30 minutes. After rinsing three times for five minutes each in $0 \cdot 1 \mathrm{M}$ TRIS-buffered saline (TBS), $\mathrm{pH} 7 \cdot 6$, sections were incubated for 30 minutes in $10 \%$ normal rabbit serum in TBS. Excess rabbit serum was then tipped off and sections were incubated overnight with the monoclonal antibody B72.3 (Cell Tech UK) at $4^{\circ} \mathrm{C}$. Sections were then rinsed in TBS as before and incubated for 30 minutes in biotinylated rabbit anti-mouse immunoglobulin at a dilution of 1 in 250 (Dakopatts). After three rinses in TBS sections were covered for 60 minutes with avidin-biotin complex horseradish

Results of histological diagnosis and B72.3 staining

\begin{tabular}{lll}
\hline Histological diagnosis & $\begin{array}{l}\text { No of } \\
\text { cases }\end{array}$ & $\begin{array}{l}\text { No of positive } \\
\text { results(\%) }\end{array}$ \\
\hline Fibrocystic change (FCC) & 29 & $17(59)$ \\
Ductal epithelial hyperplasia & 12 & $5(42)$ \\
$\quad$ Mild & 2 & $2(100)$ \\
Moderate and florid & 7 & $2(29)$ \\
Atypical & 3 & $1(33)$ \\
Lobular hyperplasia & 2 & 0 \\
Radial scar & 7 & $3(43)$ \\
Sclerosing adenosis & 3 & 0 \\
Lactational change (in FCC) & 1 & 0 \\
Intraduct papilloma & 3 & $2(67)$ \\
Fibroadenoma & 5 & $2(40)$ \\
Normal subareolar tissue & 5 & 0 \\
Normal lactating breast & 1 & 0 \\
\hline
\end{tabular}
An abstract of this article
presented at the winter meeting of the Pathological January 1990.

This work is part of D

Department of Charing Cross and

Schools, Fulham Palace Road, Londo W6 8RF

S Soomro 
Figure 1 Positive staining of apocrine metaplasia in a cyst and in two small adjacent glandular structures showing mild epithelial hyperplasia (avidin-biotin complex).

Figure 2 Positively stained normal acini (avidin-biotin complex).

Figure 3 Positively stained focus of florid ductal epithelial hyperplasia (avidin-biotin complex).
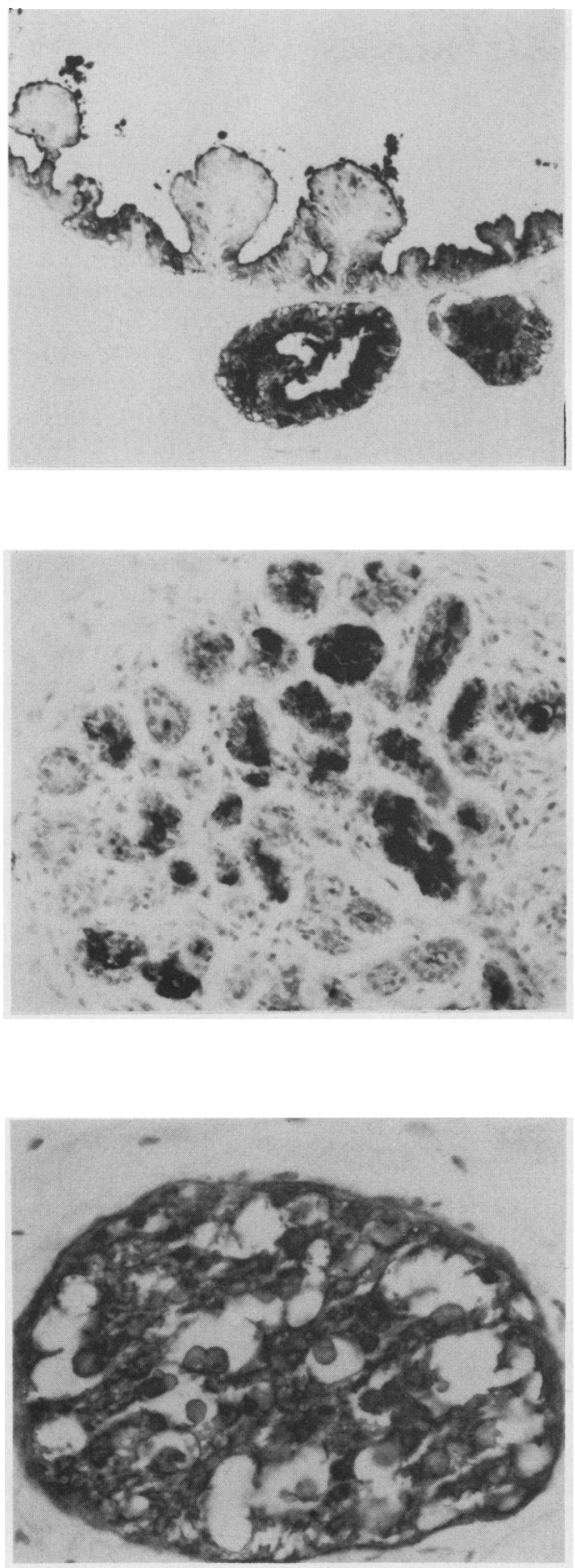

Figure 4 Stained glandular structures and fibrous tissue in a radial scar (avidin-biotin complex). peroxidase (Dakopatts). After rinsing with TBS the sites of peroxidase activity were visualised by incubating the sections in $0.05 \%$ diaminobenzidine (Sigma UK) and 0.01\% hydrogen peroxide for six minutes. Sections were then counterstained with haematoxylin, dehydrated in graded alcohols, cleared in xylene and mounted with Permount.

Control sections were treated in the same way except that the specific antiserum was replaced by TBS.

\section{Results}

Strong focal positive staining was seen in 21 of the $43(49 \%)$ cases examined. The staining was mostly seen in epithelial cells, and occasionally in luminal secretions of cysts or normal-looking ducts and acini. The only stromal staining seen was observed in the central part of a radial scar.

Two patterns of staining were noted in epithelial cells: localised lumina surface staining in cells showing apocrine metaplasia, and diffuse cytoplasmic staining in all other positive epithelial cells.

The detailed results are summarised in the table.

\section{FIBROCYSTIC CHANGE}

Positive focal staining was seen in $\mathbf{1 7}$ out of the $29(59 \%)$ cases examined. Positive staining was seen in cases with and without associated carcinoma elsewhere in the breast. All areas of apocrine metaplasia were positive (fig 1). Staining was also seen in a few normal ducts and acini (13 cases) (fig 2), in luminal secretions of some normal ducts and acini (eight cases), as well as in cysts (two cases), and in occasional areas of adenosis (one case).

The reactivity of ductal epithelial hyperplasia was variable. Thus while both foci of mild hyperplasia seen were positive (fig 1), only about a third of cases with moderate and florid hyperplasia (two out of seven) and atypical hyperplasia (one out of three) showed focal positivity (fig 3). Both cases of lobular hyperplasia examined were negative.

Focal positivity was also detected in three out of seven $(43 \%)$ radial scars. The staining was usually present in a few ducts, but in one case was also seen in the stroma occupying the central part of the lesion (fig 4). No staining was seen in three cases with sclerosing adenosis, nor in a case showing a focus of lactational change.

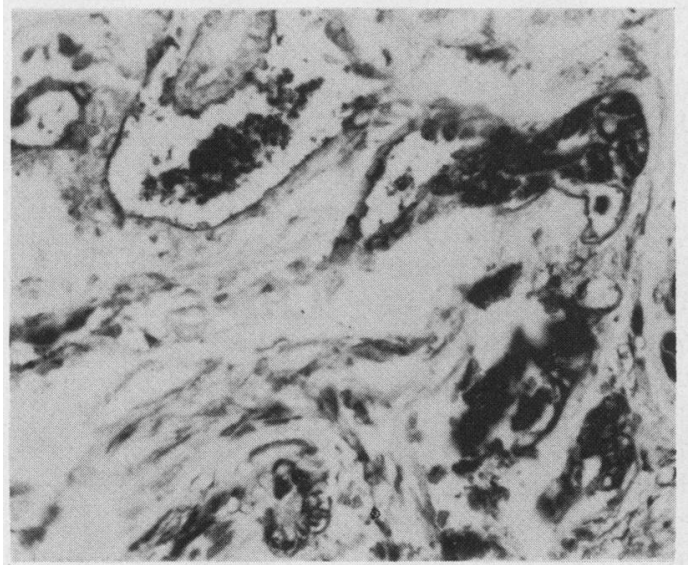

INTRADUCT PAPILLOMA

Two of the three $(67 \%)$ cases examined showed positive staining which was mainly seen in areas of apocrine metaplasia and occasionally in luminal secretions. The most extensive staining was seen in a papilloma which consisted almost entirely of metaplastic apocrine cells (fig 5).

\section{FIBROADENOMA}

Two out of the five $(40 \%)$ fibroadenomas examined showed focal positivity which was usually associated with the glandular structures 
Figure 5 Surface and luminal staining in an area of apocrine metaplasia in an intraduct papilloma (avidin-biotin complex).

Figure 6 Strongly stained glandular structures and luminal secretions in a fibroadenoma. Note absence of staining in the intracanalicular component of the lesion (left hand side of field) (avidin-biotin complex).

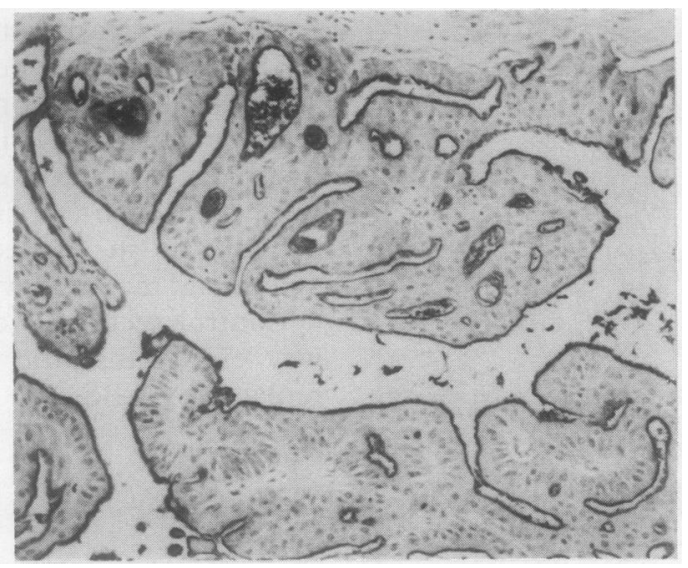

Admittedly, only a minority of cells stained in the positive cases. This may explain why the stain was originally thought to be useful as a diagnostic tool in needle aspirates. As almost half the benign lesions examined can provide false positive results, however, this is probably enough to deter us from depending on this particular immunoreactivity to guide us in deciding whether a cell is benign or malignant, especially as many malignant cells can be B72.3 negative. ${ }^{5-9}$

The clinical importance of the presence of positively stained cells in benign lesions is unclear. Our findings and those of Castagna et $a l^{9}$ suggest that almost all metaplastic apocrine cells express the antigen on their surfaces. The association between apocrine metaplasia and malignancy is controversial, but it is unlikely that metaplastic cells have a higher malignant potential than non-metaplastic cells. ${ }^{112}$

The situation is even more difficult to explain in B72.3 positive non-metaplastic cells. In haematoxylin and eosin stained sections most of these cells do not show any atypical or unusual features, but this is probably not enough to exclude the possibility that such cells may have a malignant potential that is distinct from B72.3 negative cells. In this respect we have noticed a direct association between B72.3 immunostaining and the presence of mucin in some malignant breast tumours. ${ }^{13}$ It would be interesting to investigate the possible existence of a similar relation in benign breast lesions, but this is beyond the purpose of this study.

It is concluded that B72.3 can show focal reactivity with a wide variety of normal and benign epithelial mammary structures, and it is doubtful that its use would be of any help in differentiating benign from malignant cells in fine needle aspirates.

1 Colcher D, Horan Hand PH, Nuti M, Schlom J. A spectrum of monoclonal antibodies reactive with human mammary
tumour cells. Proc Natl Acad Sci USA 1981;78:3199-203.

2 Johnson VG, Schlom J, Paterson AJ, Bennett J, Magnani JL, Colcher D. Analysis of a human tumor-associated
glycoprotein (TAG-72) identified by monoclonal glycoprotein (TAG-72) identified by

3 Muraro R, Kuroki M, Wunderlich D, et al. Generation and characterization of B72.3 second generation monoclonal antibodies reactive with the tumor-associated glycoprotein 72 antigen. Cancer Res 1988;48:4588-96.

4 Sheer DG, Schlom J, Cooper HL. Purification and composition of the human tumor-associated glycoprotein (TAG-72) defined by monoclonal antibodies CC49 and B72.3. Cancer Res 1988;48:6811-8.

5 Thor A, Ohuchi N, Szpak CA, Johnston WW, Schlom J. Distribution of oncofetal antigen tumor-associated glycoprotein-72 defined by monoclonal antibody B72.3. glycoprotein-72 defined by mon
Cancer Res 1986;46:3118-24.

6 Johnston WW, Szpak CA, Lottich SC, Thor A, Schlom J. Use of a monoclonal antibody (B72.3) as a novel immunohistochemical adjunct for the diagnosis of immunohistochemical adjunct for the diagnosis of carcinomas in fine needle as

7 Lundy J, Lozowski M, Mishriki Y. Monoclonal antibody $B 72.3$ as a diagnostic adjunct in fine needle aspirates of breast masses. Ann Surg 1986;203:399-402.

8 Kline TS, Lundy J, Lozowski M. Monoclonal antibody B72.3. An adjunct for evaluation of suspicious aspiration biopsy cytology from the breast. Cancer 1989;63:2253-6.

9 Castagna M, Nuti M, Squartini F. Mammary cancer antigen recognised by monoclonal antibody B72.3 in apocrine metaplasia of the human breast. Cancer Res 1987;47: 902-6.

10 Tavassoli FA, Jones MW, Majeste RM, Bratthauer GL, O'Leary TJ. Immunohistochemical staining with monoclonal Ab B72 3 in benign and malignant breast disease. Am J Surg Pathol 1990;14:128-33.

11 Page DL. Cancer risk assessment in benign breast biopsies. Hum Pathol 1986;17:871-4.

12 Wellings SR, Alpers CE. Apocrine cystic metaplasia: subgross pathology and prevalence in cancer-associated vergross pathology and prevalence in cancer-associated ver-
sus random autopsy breasts. Hum Pathol 1987;18:381-6.

13 Soomro S, Shousha S. Relationship between B72.3 immunostaining and histological type of breast carcinoma. $J$ Pathol 1990;160:173A. looking ducts and acini, hyperplastic duct radial scars and fibroadenomas. Some of these findings have been confirmed in a recent report. ${ }^{10}$ 